OPEN ACCESS

Edited by:

Philippe Saas,

INSERM U1098 Interactions Hôte-Greffon-Tumeur \& Ingénierie

Cellulaire et Génique, France

Reviewed by:

Shang-Rong Ji,

Lanzhou University, China Johannes Zeller,

Freiburg University Medical Center, Germany

*Correspondence: Alok Agrawal Agrawal@etsu.edu

Specialty section:

This article was submitted to Inflammation,

a section of the journal

Frontiers in Immunology

Received: 08 May 2019

Accepted: 03 July 2019

Published: 16 July 2019

Citation:

Singh SK and Agrawal A (2019)

Functionality of C-Reactive Protein for Atheroprotection

Front. Immunol. 10:1655. doi: 10.3389/fimmu.2019.01655

\section{Functionality of C-Reactive Protein for Atheroprotection}

\author{
Sanjay K. Singh and Alok Agrawal* \\ Department of Biomedical Sciences, James H. Quillen College of Medicine, East Tennessee State University, Johnson City, \\ TN, United States
}

C-reactive protein (CRP) is a pentameric molecule made up of identical monomers. CRP can be seen in three different forms: native pentameric CRP (native CRP), non-native pentameric CRP (non-native CRP), and monomeric CRP (mCRP). Both native and non-native CRP execute ligand-recognition functions for host defense. The fate of any pentameric CRP after binding to a ligand is dissociation into ligand-bound $\mathrm{mCRP}$. If ligand-bound mCRP is proinflammatory, like free mCRP has been shown to be in vitro, then $\mathrm{mCRP}$ along with the bound ligand must be cleared from the site of inflammation. Once pentameric CRP is bound to atherogenic low-density lipoprotein (LDL), it reduces both formation of foam cells and proinflammatory effects of atherogenic LDL. A CRP mutant, that is non-native CRP, which readily binds to atherogenic LDL, has been found to be atheroprotective in a murine model of atherosclerosis. Thus, unlike statins, a drug that can lower only cholesterol levels but not CRP levels should be developed. Since non-native CRP has been shown to bind to all kinds of malformed proteins in general, it is possible that non-native CRP would be protective against all inflammatory states in which host proteins become pathogenic. If it is proven through experimentation employing transgenic mice that non-native CRP is beneficial for the host, then using a small-molecule compound to target CRP with the goal of changing the conformation of endogenous native CRP would be preferred over using recombinant non-native CRP as a biologic to treat diseases caused by pathogenic proteins such as oxidized LDL.

Keywords: C-reactive protein, low-density lipoprotein, cholesterol, atherosclerosis, amyloid

\section{INTRODUCTION}

C-reactive protein (CRP) is a pentamer of identical subunits which functions in two different structural states, as native pentameric CRP (native CRP) in normal physiological environment and as non-native pentameric CRP (non-native CRP) in localized pathological and inflammatory environments (1-7). During making of CRP in the liver, first, the five subunits fold to almost a native core and the single C-terminal helix is correctly positioned. Then, the intrachain disulfide bond between $\mathrm{Cys}^{36}$ and $\mathrm{Cys}^{97}$ is formed. Further folding of the subunit is driven by the newly formed disulfide bond and $\mathrm{Ca}^{2+}$-binding. Finally, CRP is assembled as pentamers and secreted into the circulation (8). It has been shown that recombinant CRP is not assembled and not secreted from the transfected cells if there is a mutation in the region coding for its $\mathrm{Ca}^{2+}$-binding site (9). When CRP enters an inflammatory microenvironment and is exposed to pathological conditions, the data obtained from in vitro experiments suggest that the pentameric structure of CRP is converted from its native conformation to a non-native conformation $(2,10,11)$. Whether it is native CRP or 
non-native CRP, binding of CRP to a ligand causes dissociation of pentameric CRP and generation of monomeric CRP (mCRP) on the surface of the ligand (10).

Atherosclerosis is an inflammatory disease caused by the deposition and subsequent modification of low-density lipoprotein (LDL) in artery walls (12-14). Modified LDL is atherogenic: it is recognized and engulfed by macrophages to form LDL-loaded foam cells that contribute to the development of atherosclerotic lesions (14-16). It has been suggested that in areas in which inflammation takes place, including in atherosclerosis, the $\mathrm{pH}$ may be acidic due to hypoxia, lactate generation, activated macrophages and proton generation (1721). Since CRP has been found to localize with LDL and macrophages in atherosclerotic lesions in both humans and experimental animals, CRP has been implicated in modulating the pathogenesis of atherosclerosis $(22-26)$. Here, we review the literature on the structure-function relationships of CRP in vitro and in vivo as applied to atherosclerosis and conclude that CRP plays a defensive role in the pathogenesis of atherosclerosis $(27,28)$.

\section{FUNCTIONS OF CRP (NATIVE CRP) IN ATHEROSCLEROSIS}

CRP, in its native pentameric conformation and in the presence of $\mathrm{Ca}^{2+}$, binds to cells and molecules with uncovered phosphocholine ( $\mathrm{PCh}$ ) groups, such as the membrane of damaged cells and platelet-activating factor (29-31). Each subunit in the pentamer has a PCh-binding site. The three-dimensional structure and mutagenesis of the PCh-binding site revealed that $\mathrm{Glu}^{81}, \mathrm{Phe}^{66}$ and $\mathrm{Thr}^{76}$ are critical for creating the pocket on CRP to bind and accommodate PCh (32-35). Once CRP is bound to a PChcontaining ligand, it activates the classical complement pathway (36).

Many kinds of modifications can occur to deposited LDL in arteries; however, two types of modified LDL prepared in vitro, oxidized LDL (ox-LDL) and enzymatically-modified LDL (E$\mathrm{LDL}$ ), are mostly used in experiments to define the role of CRP in atherosclerosis (37-39). Since the PCh groups present in LDL are exposed in E-LDL, CRP is able to bind to ELDL in a $\mathrm{Ca}^{2+}$-dependent manner $(40,41)$. CRP does not bind to ox-LDL; however, CRP can bind to ox-LDL if LDL is oxidized enough to expose its PCh moiety (42-45). If CRP binds to ox-LDL independent of the exposure of PCh on oxLDL, it would be possible only in a pathological milieu that can affect CRP structurally $(10,11)$. CRP has also been shown to bind to complexes consisting of ox-LDL and $\beta 2$-glycoprotein I $(46,47)$. CRP also binds to cholesterol crystals and it has been shown that CRP is located mainly in the cholesterolrich necrotic core in atherosclerotic lesions (48). It has been

Abbreviations: CRP, C-reactive protein; CRP or native CRP, native pentameric CRP; non-native CRP, non-native pentameric CRP; mCRP, monomeric CRP; LDL, low-density lipoprotein; ox-LDL, oxidized LDL; E-LDL, enzymatically-modified LDL; PCh, phosphocholine. shown that CRP also binds to LOX-1 which is a receptor for ox-LDL $(49,50)$.

CRP, ox-LDL and E-LDL all are known to be involved in interrelated pathophysiological pathways including in the formation of LDL-loaded macrophage foam cells $(16,51)$. However, the literature on the effects of CRP on the formation of foam cells has been controversial. Since CRP was found to be located intracellularly in foam cells, it was hypothesized that CRP complexes with LDL, enhances the binding of LDL to macrophages, and thus facilitates the cellular uptake of LDL along with CRP (52-57). When pure complexes of CRP and E-LDL were used for treatment of macrophages, it was found that CRP-bound E-LDL was unable to form foam cells, clearly suggesting for the first time that CRP possesses the ability to prevent the formation of foam cells (58). Indeed, in another study, the complexes of CRP and LDL were found to be unable to enter macrophages (59). In addition, when endothelial cells and a third type of modified LDL, acetylated LDL, were used in foam cell experiments, mCRP was found to decrease the uptake of acetylated LDL by endothelial cells (60). In another study employing endothelial cells as a model for foam cell formation, CRP was found to increase LDL transcytosis across endothelial cells (61). mCRP has also been shown to decrease uptake of ox-LDL by macrophages and it has been proposed that the interaction of MCRP with oxLDL may contribute to retardation of the foam cell formation by reducing the aggressive macrophage response to ox-LDL $(43,62)$. Additionally, it has been proposed that mCRP may exert a protective role by facilitating the clearance of retained native LDL from extracellular space, and thus lower the risk of LDL modifications (43). But, since foam cell formation is inhibited whenever CRP is complexed with modified LDL such as CRP-E-LDL and mCRP-acetylated LDL, it has been proposed that if each LDL molecule retained in the arterial wall becomes CRP-bound, the development of atherosclerosis should be retarded (58).

Besides the effects of CRP on the formation of foam cells, other consequences of the interactions between CRP and modified LDL have been reported, although it is unclear whether it was ensured that CRP was free of spontaneously generated mCRP. CRP, after binding to LDL, causes charge modification of LDL (59). The production of proinflammatory cytokines by macrophages decreases when the cells are treated with a combination of CRP and ox-LDL (62). CRP inhibits the susceptibility of copperinduced oxidation of LDL, that is, once CRP is bound to ox-LDL, further oxidation is prevented, and CRP does so by prolonging the time it takes for copper ions to oxidize LDL $(63,64)$. By sequestering minimally modified LDL (mmLDL), CRP can prevent binding of mmLDL to monocytes and attenuate mmLDL-induced monocyte adhesion and activation (65). CRP was also found to suppress the proatherogenic effects of macrophages when bound to lysophosphatidylcholine present in ox-LDL and inhibit the association of ox-LDL to macrophages; this effect may in part retard the progression of atherosclerosis (66). These findings suggest that not only does CRP prevent foam cell formation but also reduce the proinflammatory effects of modified LDL and foam cells. 
Human CRP, mouse CRP and rabbit CRP have all been used to determine the effects of CRP on the development of atherosclerosis. For human CRP, three different murine models of atherosclerosis, $A p o E^{-/-}$mice, $L D L r^{-/-}$mice and $A p o B^{100 / 100} \mathrm{LDLr}^{-/-}$mice, and a rabbit model of atherosclerosis have been employed. CRP was either transgenic or passively administered. In most studies employing $A p o E^{-/-}$mice, CRP was found to be neither proatherogenic nor atheroprotective: both passively administered human CRP and transgenically expressed human CRP had no effect on the development, progression, or severity of atherosclerosis (67-71). In two studies employing $A p o E^{-/-}$mice, CRP slightly worsened the disease (72, 73). In another study employing $A p o E^{-/-}$mice, CRP promoted early changes of atherosclerosis by directly increasing the transcytosis of LDL across endothelial cells and increasing LDL retention in vascular walls (61). In $L D L r^{-/-}$mice also, there was no effect of CRP on the development of atherosclerosis (74). When $A p o B^{100 / 100} L D L r^{-/-}$mice were employed, which are rich in LDL and develop human-like hypercholesterolemia, CRP slowed the development of atherosclerosis, suggesting an atheroprotective role of CRP (75). In the rabbit model of atherosclerosis also, there was no effect of transgenic human CRP on either aortic or coronary atherosclerotic lesion formation (76). CRP-deficient mice were employed to observe any possible role of endogenous murine CRP in atherosclerosis (77). In both $A p o E^{-/-} C R P^{-/-}$and $L D L r^{-/-} C R P^{-/-}$mice, the size of atherosclerotic lesions was either equivalent or increased when compared to that of $A p o E^{-/-}$and $L D L r^{-/-}$mice, suggesting that murine CRP had the ability to mediate atheroprotective effects (77). Besides human and murine CRP, the effect of rabbit CRP on the development of atherosclerosis in rabbits has also been investigated by using CRP antisense oligonucleotides (78). CRP antisense oligonucleotide treatment led to a significant reduction of CRP levels in rabbits; however, both aortic and coronary atherosclerotic lesions were not significantly changed, suggesting that inhibition of plasma CRP does not affect the development of atherosclerosis in rabbits (78). The combined data suggest that native CRP was either incapable or only partly capable for protecting against atherosclerosis in animal models.

\section{FUNCTIONS OF NON-NATIVE PENTAMERIC CRP (NON-NATIVE CRP) IN ATHEROSCLEROSIS}

In the presence of a biological protein modifier, the structure of CRP is altered leading to the production of non-native CRP which ultimately generates mCRP $(1-5,79)$. Dissociation of CRP to mCRP thus involves an intermediate stage of nonnative CRP, and it has been shown that antibodies specific for mCRP react with non-native CRP also (1). There are several modifiers of CRP structure. CRP is modified in the presence of abundant damaged cell membranes (1). The binding of CRP to activated platelets and apoptotic cells has also been shown to change the structure of CRP to generate $\operatorname{mCRP}(80,81)$. CRP, by binding to cell-derived microvesicles, undergoes a structural change without disrupting the pentameric symmetry and constitutes the major CRP species deposited in inflamed tissue (4). mCRP has also been seen deposited at burn wounds having necrotic and inflamed tissue (82). Acidic $\mathrm{pH}$ condition modifies CRP $(10,83)$. CRP is also modified by hydrogen peroxide and hypochlorous acid $(11,84)$. Hypochlorous acid modifies CRP by oxidation and chlorination of amino acids, leading to protein unfolding, greater surface hydrophobicity and the formation of aggregates (84). These findings suggest that when CRP enters an inflammatory microenvironment and is exposed to pathological conditions, the structure of CRP is changed first to a non-native pentameric conformation leading to complete dissociation of CRP and generation of mCRP.

Except for binding to $\mathrm{PCh}$, the recognition functions of nonnative CRP are different from those of CRP $(2,7)$. One function of CRP in its non-native pentameric conformation is to bind to modified LDL irrespective of the presence of $\mathrm{PCh}$ and $\mathrm{Ca}^{2+}$. Unlike CRP, non-native CRP readily binds to ox-LDL regardless of the extent and nature of the oxidation status $(10,11)$. To ELDL, non-native CRP binds more avidly than CRP does (83). It has also been shown that, in the absence of $\mathrm{Ca}^{2+}$, a new lysophosphatidylcholine-binding site located on the opposite side of the known PCh-binding site becomes functional $(85,86)$. The binding to and actions of CRP on endothelial cells also requires a conformational rearrangement in CRP (87). Taken together, the deposition of CRP and its co-localization with LDL in atherosclerotic lesions indicate the presence of nonnative CRP at the lesions. Besides PCh, the other moieties on LDL molecules that interact with CRP include apolipoprotein $\mathrm{B}$ and cholesterol. However, the moiety on modified LDL with which non-native CRP interacts is unknown (88-90). The binding site on non-native CRP for modified LDL has not been elucidated as yet either. It has been proposed though that the binding site may involve amino acid residues participating in the formation of intersubunit contact region since this region is buried in CRP and accessible in non-native CRP $(2,10)$. In addition, a single sequence motif called the cholesterol binding sequence, from amino acid residue 35 to 47, has been found to be responsible for mediating the interactions of mCRP with diverse ligands. The versatility of the cholesterol binding sequence appears to originate from its intrinsically disordered conformation (91).

Although the investigations to determine the effects of CRP on the development of atherosclerosis in animals provide conflicting results, a study employing mCRP in $A p o E^{-/-}$mice indicated that $\mathrm{mCRP}$ was atheroprotective (73). Additionally, the data obtained from in vitro experiments raised hopes that non-native CRP may be more atheroprotective than CRP, considering the difference between the LDL-binding recognition functions of CRP and non-native CRP. Employing site-directed mutagenesis, it was possible to create CRP mutants capable of binding to ox-LDL without the requirement of any further structural change, and one such mutant has been reported earlier (92). Recently, the impact of such a CRP mutant on the development of atherosclerosis was evaluated employing the $\mathrm{LDLr}^{-/-}$mouse model of atherosclerosis (93). The development 
of atherosclerotic lesions in the whole aorta was reduced in mice receiving mutant CRP that had a non-native pentameric structure. Considering the findings made on all forms of CRP structure, it seems clear that CRP is an atheroprotective molecule (93).

\section{PROINFLAMMATORY FUNCTIONS OF LIGAND-BOUND MCRP}

Once CRP, either native or non-native, is bound to certain types of ligands, mCRP is generated on the surface of the ligand, due to complete dissociation of the five subunits of CRP. It has been shown that the binding of non-native CRP to immobilized protein ligands results in expression of MCRP epitopes and that mCRP cannot be detached from the ligand (10). Thus, mCRP is not a free molecule; instead, MCRP is always ligand-bound and found in CRP-derived debris. The presence of MCRP can be detected at the sites where CRP-ligands are present. The detection of autoantibodies against mCRP provided further evidence for the in vivo existence of non-native CRP and mCRP, probably ligand-bound (94-96). The mCRP form is the predominant form of CRP existing in atherosclerotic lesions (80, 97-100). It has also been shown that the expression of proinflammatory properties of CRP requires sequential conformational changes beginning with the loss of pentameric symmetry, followed by reduction of the intrasubunit disulfide bond, generating $\operatorname{mCRP}(87,101)$. Since free $\mathrm{mCRP}$ is proinflammatory in in vitro experiments, it can only be assumed that ligand-bound mCRP may also be proinflammatory. Ligand-associated $\mathrm{MCRP}$ must be removed along with the ligand.

\section{CRP, STATINS, AND ATHEROSCLEROSIS}

Statins, the inhibitors of a key enzyme in the cholesterol biosynthesis pathway, are used in humans as cholesterollowering drugs (102). However, statins also lower CRP levels in humans and human CRP-transgenic mice (103-108). Statins lower CRP levels independently of their cholesterol-lowering activity $(103,104)$. Statins lower CRP by inhibiting the biosynthesis of CRP by hepatocytes $(109,110)$. Nitric oxide also inhibits the biosynthesis of CRP (109). It is possible that nitric oxide acts as the mediator of the CRP-lowering effect of statins, since statins are known to generate nitric oxide production (109112). Because CRP is beneficial, to get rid of CRP from the circulation is not a good idea; a drug that can lower cholesterol levels, but not the CRP levels, should be of choice over statins which lower both $(113,114)$.

\section{CONCLUSIONS}

CRP appears in the body in response to inflammation and CRP requires exposure to an inflammatory milieu to change its structure and execute functions $(2,115)$. We have hypothesized earlier that one of the functions of CRP at sites of inflammation is to sense the inflammatory microenvironment, change its own structure in response but remain pentameric, and then bind to pathogenic proteins deposited at those sites (11). CRP does not show an effect on the development of atherosclerosis likely because the inflammatory microenvironment in the arterial wall in animal models of atherosclerosis may not be appropriate in terms of $\mathrm{pH}$ and redox conditions and, therefore, the structure of CRP remains unchanged. Consistent with this hypothesis, a CRP molecule which was modified in vitro and was capable of binding to atherogenic LDL, did reduce the development of atherosclerosis in mice (93). Thus, CRP has atheroprotective functions displayed by its non-native pentameric form. It has also been proposed that CRP-mediated lipoprotein removal likely underlies the regression of early lesions and perhaps CRP should be considered as an antiatherogenic agent (39).

Non-native CRP binds not only to atherogenic LDL but to all immobilized proteins, including proteins that might be deposited in the host body or recruited on pathogenic surfaces $(10,116)$. We have suggested previously that deposited, aggregated and conformationally denatured proteins expose a CRP-ligand, regardless of the protein's identity (10). Accordingly, non-native CRP has also been found to be protective against pneumococcal infection (117-119). Although it is not clear what structure on immobilized proteins is recognized by non-native CRP, it has been proposed that an amyloid-like structure is formed on all such proteins and that is what is being recognized by non-native CRP, consistent with the hypothesis that CRP is a pattern recognition molecule of the innate immune system (10). Indeed, an amyloid-like structure appears on LDL by oxidation $(120,121)$. Non-native CRP may serve as a tool to investigate the functions of CRP in every inflammatory disease involving deposition and aggregation of proteins, such as amyloidosis and autoimmune diseases (122). CRP may have been conserved throughout evolution for protection against disease and toxicity caused by protein misfolding and conformationally altered pathogenic proteins $(123,124)$.

Considering all the properties of all forms of CRP, it can be said that CRP possesses the functionality of a host defense molecule against not only atherosclerosis but against all diseases caused by proteins when proteins behave like a pathogen or a toxic molecule, in a life cycle that begins as free CRP in circulation and ends in ligand-bound mCRP at sites of inflammation via an intermediate stage of non-native pentamers. If it is validated through further experimentation employing mice transgenic for non-native CRP that non-native CRP is beneficial, the focus should be on the designing and synthesis of a small-molecule compound to target CRP with the goal of changing the conformation of endogenous CRP, which would be preferred over using recombinant non-native CRP as a biologic to treat diseases caused by pathogenic proteins such as ox-LDL.

\section{AUTHOR CONTRIBUTIONS}

All authors listed have made a substantial, direct and intellectual contribution to the work, and approved it for publication. 


\section{FUNDING}

This work was supported by National Institutes of Health grant AR068787 to AA.

\section{REFERENCES}

1. Ji S-R, Wu Y, Zhu L, Potempa LA, Sheng F-L, Lu W, et al. Cell membranes and liposomes dissociate C-reactive protein (CRP) to form a new, biologically active structural intermediate: $\mathrm{mCRP}_{\mathrm{m}}$. FASEB J. (2007) 21:284-94. doi: 10.1096/fj.06-6722com

2. Agrawal A, Gang TB, Rusiñol AE. Recognition functions of pentameric C-reactive protein in cardiovascular disease. Mediators Inflamm. (2014) 2014:319215. doi: 10.1155/2014/319215

3. Wu Y, Potempa LA, El Kebir D, Filep JG. C-reactive protein and inflammation: conformational changes affect function. Biol Chem. (2015) 396:1181-97. doi: 10.1515/hsz-2015-0149

4. Braig D, Nero TL, Koch H-G, Kaiser B, Wang X, Thiele JR, et al. Transitional changes in the CRP structure lead to the exposure of proinflammatory binding sites. Nat Commun. (2017) 8:14188. doi: 10.1038/ncomms14188

5. McFadyen JD, Kiefer J, Braig D, Loseff-Silver J, Potempa LA, Eisenhardt SU. Dissociation of C-reactive protein localizes and amplifies inflammation: evidence for a direct biological role of Creactive protein and its conformational changes. Front Immunol. (2018) 9:1351. doi: 10.3389/fimmu.2018.01351

6. Salazar J, Martínez MS, Chávez-Castillo M, Núñez V, Añez R, Torres Y, et al. C-reactive protein: an in-depth look into structure, function, and regulation. Int Sch Res Notices. (2014) 2014:653045. doi: 10.1155/2014/653045

7. Lv J-M, Wang M-Y. In vitro generation and bioactivity evaluation of C-reactive protein intermediate. PLoS ONE. (2018) 13:e0198375. doi: 10.1371/journal.pone.0198375

8. Lv J-M, Lü S-Q, Liu Z-P, Zhang J, Gao B-X, Yao Z-Y, et al. Conformational folding and disulfide bonding drive distinct stages of protein structure formation. Sci Rep. (2018) 8:1494. doi: 10.1038/s41598-018-20014-y

9. Suresh MV, Singh SK, Agrawal A. Interaction of calcium-bound C-reactive protein with fibronectin is controlled by $\mathrm{pH}$ : in vivo implications. J Biol Chem. (2004) 279:52552-7. doi: 10.1074/jbc.M409054200

10. Hammond DJ Jr, Singh SK, Thompson JA, Beeler BW, Rusiñol AE, Pangburn MK, et al. Identification of acidic pH-dependent ligands of pentameric C-reactive protein. J Biol Chem. (2010) 285:3623544. doi: 10.1074/jbc.M110.142026

11. Singh SK, Thirumalai A, Pathak A, Ngwa DN, Agrawal A. Functional transformation of C-reactive protein by hydrogen peroxide. J Biol Chem. (2017) 292:3129-36. doi: 10.1074/jbc.M116.773176

12. Libby P. Inflammation in atherosclerosis. Nature. (2002) 420:86874. doi: 10.1038/nature01323

13. Galkina E, Ley K. Immune and inflammatory mechanisms of atherosclerosis. Annu Rev Immunol. (2009) 27:16597. doi: 10.1146/annurev.immunol.021908.132620

14. Lu H, Daugherty A. Atherosclerosis: cell biology and lipoproteins. Curr Opin Lipidol. (2013) 24:455-6. doi: 10.1097/MOL.0b013e3283654ef9

15. Moore KJ, Tabas I. Macrophages in the pathogenesis of atherosclerosis. Cell. (2011) 145:341-55. doi: 10.1016/j.cell.2011.04.005

16. Orsó E, Grandl M, Schmitz G. Oxidized LDL-induced endolysosomal phospholipidosis and enzymatically modified LDLinduced foam cell formation determine specific lipid species modulation in human macrophages. Chem Phys Lipids. (2011) 164:479-87. doi: 10.1016/j.chemphyslip.2011.06.001

17. Leake DS. Does an acidic $\mathrm{pH}$ explain why low density lipoprotein is oxidised in atherosclerotic lesions? Atherosclerosis. (1997) 129:14957. doi: 10.1016/S0021-9150(96)06035-2

18. Björnheden T, Levin M, Evaldsson M, Wiklund O. Evidence of hypoxic areas within the arterial wall in vivo. Arterioscler Thromb Vasc Biol. (1999) 19:870-6. doi: 10.1161/01.ATV.19.4.870

\section{ACKNOWLEDGMENTS}

We are grateful to Irving Kushner, M.D., for reviewing the manuscript and for his helpful suggestions.

19. Naghavi M, John R, Naguib S, Siadaty MS, Grasu R, Kurian KC, et al. $\mathrm{pH}$ heterogeneity of human and rabbit atherosclerotic plaques: a new insight into detection of vulnerable plaque. Atherosclerosis. (2002) 164:2735. doi: 10.1016/S0021-9150(02)00018-7

20. Sneck M, Kovanen PT, Öörni K. Decrease in pH strongly enhances binding of native, proteolyzed, lipolyzed, and oxidized low density lipoprotein particles to human aortic proteoglycans. J Biol Chem. (2005) 280:3744954. doi: 10.1074/jbc.M508565200

21. Haka AS, Grosheva I, Chiang E, Buxbaum AR, Baird BA, Pierini LM, et al. Macrophages create an acidic extracellular hydrolytic compartment to digest aggregated lipoproteins. Mol Biol Cell. (2009) 20:4932-40. doi: 10.1091/mbc.e09-07-0559

22. Torzewski J, Torzewski M, Bowyer DE, Fröhlich M, Koenig W, Waltenberger $J$, et al. C-reactive protein frequently colocalizes with the terminal complement complex in the intima of early atherosclerotic lesions of human coronary arteries. Arterioscler Thromb Vasc Biol. (1998) 18:138692. doi: 10.1161/01.ATV.18.9.1386

23. Zhang YX, Cliff WJ, Schoefl GI, Higgins G. Coronary C-reactive protein distribution: its relation to development of atherosclerosis. Atherosclerosis. (1999) 145:375-9. doi: 10.1016/S0021-9150(99)00105-7

24. Sun H, Koike T, Ichikawa T, Hatakeyama K, Shiomi M, Zhang B, et al. C-reactive protein in atherosclerotic lesions: its origin and pathophysiological significance. Am J Pathol. (2005) 167:1139-48. doi: 10.1016/S0002-9440(10)61202-3

25. Norja S, Nuutila L, Karhunen PJ, Goebeler S. C-reactive protein in vulnerable coronary plaques. J Clin Pathol. (2007) 60:545-8. doi: 10.1136/jcp.2006.038729

26. Yu Q, Li Y, Wang Y, Zhao S, Yang P, Chen Y, et al. C-reactive protein levels are associated with the progression of atherosclerotic lesions in rabbits. Histol Histopathol. (2012) 27:529-35. doi: 10.1155/2012/506159

27. Singh SK, Suresh MV, Voleti B, Agrawal A. The connection between C-reactive protein and atherosclerosis. Ann Med. (2008) 40:110-20. doi: 10.1080/07853890701749225

28. Agrawal A, Hammond DJ Jr, Singh SK. Atherosclerosis-related functions of C-reactive protein. Cardiovasc Haematol Disord Drug Targets. (2010) 10:235-40. doi: 10.2174/187152910793743841

29. Volanakis JE, Kaplan MH. Specificity of C-reactive protein for choline phosphate residues of pneumococcal C-polysaccharide. Proc Soc Exp Biol Med. (1971) 136:612-4. doi: 10.3181/00379727-136-35323

30. Volanakis JE, Wirtz KWA. Interaction of C-reactive protein with artificial phosphatidylcholine bilayers. Nature. (1979) 281:155-7. doi: 10.1038/281155a0

31. Black S, Wilson A, Samols D. An intact phosphocholine binding site is necessary for transgenic rabbit $\mathrm{C}$-reactive protein to protect mice against challenge with platelet-activating factor. J Immunol. (2005) 175:11926. doi: 10.4049/jimmunol.175.2.1192

32. Shrive AK, Cheetham GMT, Holden D, Myles DAA, Turnell WG, Volanakis JE, et al. Three-dimensional structure of human C-reactive protein. Nat Struct Biol. (1996) 3:346-54. doi: 10.1038/nsb0496-346

33. Thompson D, Pepys MB, Wood S. The physiological structure of human C-reactive protein and its complex with phosphocholine. Structure. (1999) 7:169-77. doi: 10.1016/S0969-2126(99)80023-9

34. Agrawal A, Lee S, Carson M, Narayana SVL, Greenhough TJ, Volanakis JE. Site-directed mutagenesis of the phosphocholine-binding site of human C-reactive protein: Role of Thr ${ }^{76}$ and Trp ${ }^{67}$. J Immunol. (1997) 158:345-50.

35. Agrawal A, Simpson MJ, Black S, Carey MP, Samols D. A Creactive protein mutant that does not bind to phosphocholine and pneumococcal C-polysaccharide. J Immunol. (2002) 169:321722. doi: 10.4049/jimmunol.169.6.3217 
36. Kaplan MH, Volanakis JE. Interaction of C-reactive protein complexes with the complement system. I. Consumption of human complement associated with the reaction of C-reactive protein with pneumococcal C-polysaccharide and with the choline phosphatides, lecithin and sphingomyelin. J. Immunol. (1974) 112:2135-47.

37. Levitan I, Volkov S, Subbaiah PV. Oxidized LDL: Diversity, patterns of recognition, and pathophysiology. Antioxid Redox Signal. (2010) 13:3975. doi: 10.1089/ars.2009.2733

38. Tsimikas S, Miller YI. Oxidative modification of lipoproteins: Mechanisms, role in inflammation and potential clinical applications in cardiovascular disease. Curr Pharm Des. (2011) 17:27-37. doi: $10.2174 / 138161211795049831$

39. Torzewski M. Enzymatically modified LDL, atherosclerosis and beyond: paving the way to acceptance. Front Biosci. (2018) 23:1257-71. doi: $10.2741 / 4642$

40. Bhakdi S, Torzewski M, Klouche M, Hemmes M. Complement and atherogenesis: binding of CRP to degraded, nonoxidized LDL enhances complement activation. Arterioscler Thromb Vasc Biol. (1999) 19:234854. doi: 10.1161/01.ATV.19.10.2348

41. He W, Ren Y, Wang X, Chen Q, Ding S. C-reactive protein and enzymatically modified LDL cooperatively promote dendritic cell-mediated $\mathrm{T}$ cell activation. Cardiovasc Pathol. (2017) 29:1-6. doi: 10.1016/j.carpath.2017.03.009

42. De Beer FC, Soutar AK, Baltz ML, Trayner IM, Feinstein A, Pepys MB. Low density lipoprotein and very low density lipoprotein are selectively bound by aggregated C-reactive protein. J Exp Med. (1982) 156:23042. doi: 10.1084 /jem.156.1.230

43. Ji S-R, Wu Y, Potempa LA, Qiu Q, Zhao J. Interactions of C-reactive protein with low-density lipoproteins: Implications for an active role of modified C-reactive protein in atherosclerosis. Int J Biochem Cell Biol. (2006) 38:648-61. doi: 10.1016/j.biocel.2005.11.004

44. Chang M-K, Binder CJ, Torzewski M, Witztum JL. C-reactive protein binds to both oxidized LDL and apoptotic cells through recognition of a common ligand: Phosphorylcholine of oxidized phospholipids. Proc Natl Acad Sci USA. (2002) 99:13043-8. doi: 10.1073/pnas.192399699

45. Biró A, Thielens NM, Cervenák L, Prohászka Z, Füst G, Arlaud GJ. Modified low density lipoproteins differentially bind and activate the $\mathrm{C} 1$ complex of complement. Mol Immunol. (2007) 44:1169-77. doi: 10.1016/j.molimm.2006.06.013

46. Zhang R, Zhou S-J, Li C-J, Wang X-N, Tang Y-Z, Chen R, et al. Creactive protein/oxidised low-density lipoprotein/ $\beta 2$-glycoprotein I complex promotes atherosclerosis in diabetic $\mathrm{BALB} / \mathrm{c}$ mice via p38mitogenactivated protein kinase signal pathway. Lipids Health Dis. (2013) 12:42. doi: 10.1186/1476-511X-12-42

47. Wang J, Feng M-J, Zhang R, Yu D-M, Zhou S-J, Chen R, et al. C-reactive protein/oxidized low density lipoprotein $/ \beta_{2}$-glycoprotein I complexes induce lipid accumulation and inflammatory reaction in macrophages via $\mathrm{p} 38 /$ mitogen-activated protein kinase and nuclear factor-кB signaling pathways. Mol Med Rep. (2016) 14:3490-8. doi: 10.3892/mmr.2016.5622

48. Pilely K, Fumagalli S, Rosbjerg A, Genster N, Skjoedt M-O, Perego C, et al. C-reactive protein binds to cholesterol crystals and co-localizes with the terminal complement complex in human atherosclerotic plaques. Front Immunol. (2017) 8:1040. doi: 10.3389/fimmu.2017.01040

49. Fujita Y, Kakino A, Nishimichi N, Yamaguchi S, Sato Y, Machida $\mathrm{S}$, et al. Oxidized LDL receptor LOX-1 binds to C-reactive protein and mediates its vascular effects. Clin Chem. (2009) 55:285-94. doi: 10.1373/clinchem.2008.119750

50. Shih HH, Zhang S, Cao W, Hahn A, Wang J, Paulsen JE, et al. CRP is a novel ligand for the oxidized LDL receptor LOX-1. Am J Physiol Heart Circ Physiol. (2009) 296:H1643-50. doi: 10.1152/ajpheart.00938.2008

51. Obradovic MM, Trpkovic A, Bajic V, Soskic S, Jovanovic A, Stanimirovic J, et al. Interrelatedness between C-reactive protein and oxidized low-density lipoprotein. Clin Chem Lab Med. (2015) 53:29-34. doi: 10.1515/cclm-2014-0590

52. Zwaka TP, Hombach V, Torzewski J. C-reactive protein-mediated low density lipoprotein uptake by macrophages: implications for atherosclerosis. Circulation. (2001) 103:1194-7. doi: 10.1161/01.CIR.103.9.1194
53. Fu T, Borensztajn J. Macrophage uptake of low-density lipoprotein bound to aggregated C-reactive protein: possible mechanism of foamcell formation in atherosclerotic lesions. Biochem J. (2002) 366:195201. doi: 10.1042/bj20020045

54. Verma S, Li S-H, Badiwala MV, Weisel RD, Fedak PWM, Li R-K, et al. Endothelin antagonism and interleukin-6 inhibition attenuate the proatherogenic effects of C-reactive protein. Circulation. (2002) 105:18906. doi: 10.1161/01.CIR.0000015126.83143.B4

55. Van Tits L, de Graaf J, Toenhake H, van Heerde W, Stalenhoef A. C-reactive protein and annexin A5 bind to distinct sites of negatively charged phospholipids present in oxidized lowdensity lipoprotein. Arterioscler Thromb Vasc Biol. (2005) 25:717-22. doi: 10.1161/01.ATV.0000157979.51673.2c

56. Singh U, Dasu MR, Yancey PG, Afify A, Devaraj S, Jialal I. Human C-reactive protein promotes oxidized low density lipoprotein uptake and matrix metalloproteinase-9 release in Wistar rats. J Lipid Res. (2008) 49:101523. doi: 10.1194/jlr.M700535-JLR200

57. Torzewski M, Rist C, Mortensen RF, Zwaka TP, Bienek M, Waltenberger $\mathrm{J}$, et al. C-reactive protein in the arterial intima: role of C-reactive protein receptor-dependent monocyte recruitment in atherogenesis. Arterioscler Thromb Vasc Biol. (2000) 20:2094-9. doi: 10.1161/01.ATV.20.9.2094

58. Singh SK, Suresh MV, Prayther DC, Moorman JP, Rusiñol AE, Agrawal A. Creactive protein-bound enzymatically modified low-density lipoprotein does not transform macrophages into foam cells. J Immunol. (2008) 180:431622. doi: 10.4049/jimmunol.180.6.4316

59. Mookerjea S, Francis J, Hunt D, Yong CY, Nagpurkar A. Rat Creactive protein causes a charge modification of LDL and stimulates its degradation by macrophages. Arterioscler Thromb. (1994) 14:2827. doi: 10.1161/01.ATV.14.2.282

60. Schwedler SB, Hansen-Hagge T, Reichert M, Schmiedeke D, Schneider $\mathrm{R}$, Galle J, et al. Monomeric C-reactive protein decreases acetylated LDL uptake in human endothelial cells. Clin Chem. (2009) 55:172831. doi: 10.1373 /clinchem.2009.125732

61. Bian F, Yang X, Zhou F, Wu P-H, Xing S, Xu G, et al. C-reactive protein promotes atherosclerosis by increasing LDL transcytosis across endothelial cells. Br J Pharmacol. (2014) 171:2671-84. doi: 10.1111/bph.12616

62. Krayem I, Bazzi S, Karam M. The combination of CRP isoforms with oxLDL decreases TNF- $\alpha$ and IL- 6 release by U937-derived macrophages. Biomed Rep. (2017) 7:272-6. doi: 10.3892/br.2017.949

63. Rufail ML, Ramage SC, van Antwerpen R. C-reactive protein inhibits in vitro oxidation of low-density lipoprotein. FEBS Lett. (2006) 580:515560. doi: 10.1016/j.febslet.2006.08.045

64. Nayeri H, Naderi GA, Moghadam MS, Mohamadzadeh S, Boshtam M, Dinani NJ, et al. Effect of CRP on some of the in vitro physicochemical properties of LDL. ARYA Atheroscler. (2010) 6:85-9.

65. Eisenhardt SU, Starke J, Thiele JR, Murphy A, Stark GB, Bassler N, et al. Pentameric CRP attenuates inflammatory effects of mmLDL by inhibiting mmLDL-monocyte interactions. Atherosclerosis. (2012) 224:38493. doi: 10.1016/j.atherosclerosis.2012.07.039

66. Chang M-K, Hartvigsen K, Ryu J, Kim Y, Han KH. The pro-atherogenic effects of macrophages are reduced upon formation of a complex between C-reactive protein and lysophosphatidylcholine. J Inflamm. (2012) 9:42. doi: 10.1186/1476-9255-9-42

67. Hirschfield GM, Gallimore JR, Kahan MC, Hutchinson WL, Sabin CA, Benson GM, et al. Transgenic human C-reactive protein is not proatherogenic in apolipoprotein E-deficient mice. Proc Natl Acad Sci USA. (2005) 102:8309-14. doi: 10.1073/pnas.0503202102

68. Reifenberg K, Lehr H-A, Baskal D, Wiese E, Schaefer SC, Black $\mathrm{S}$, et al. Role of C-reactive protein in atherogenesis: can the apolipoprotein E knockout mouse provide the answer? Arterioscler Thromb Vasc Biol. (2005) 25:1641-6. doi: 10.1161/01.ATV.0000171983.95 612.90

69. Trion A, de Matt MPM, Jukema JW, van der Laarse A, Mass $\mathrm{MC}$, Offerman EH, et al. No effect of C-reactive protein on early atherosclerosis development in apolipoprotein $\mathrm{E}^{*}$ 3-leiden/human C-reactive protein transgenic mice. Arterioscler Thromb Vasc Biol. (2005) 25:163540. doi: 10.1161/01.ATV.0000171992.36710.1e 
70. Tennent GA, Hutchinson WL, Kahan MC, Hirschfield GM, Gallimore JR, Lewin J, et al. Transgenic human CRP is not pro-atherogenic, proatherothrombotic or pro-inflammatory in apoE $\mathrm{E}^{--/-}$mice. Atherosclerosis. (2008) 196:248-55. doi: 10.1016/j.atherosclerosis.2007.05.010

71. Ortiz MA, Campana GL, Woods JR, Boguslawski G, Sosa MJ, Walker $\mathrm{CL}$, et al. Continuously-infused human C-reactive protein is neither proatherosclerotic nor proinflammatory in apolipoprotein E-deficient mice. Exp Biol Med. (2009) 234:624-31. doi: 10.3181/0812-RM-347

72. Paul A, Ko KWS, Li L, Yechoor V, McCrory MA, Szalai $\mathrm{AJ}$, et al. C-reactive protein accelerates the progression of atherosclerosis in apolipoprotein E-deficient mice. Circulation. (2004) 109:647-55. doi: 10.1161/01.CIR.0000114526.50618.24

73. Schwedler SB, Amann K, Wernicke K, Krebs A, Nauck M, Wanner C, et al. Native C-reactive protein increases whereas modified C-reactive protein reduces atherosclerosis in apolipoprotein E-knockout mice. Circulation. (2005) 112:1016-23. doi: 10.1161/CIRCULATIONAHA.105.556530

74. Torzewski M, Reifenberg K, Cheng F, Wiese E, Küpper I, Crain J, et al. No effect of C-reactive protein on early atherosclerosis in $\mathrm{LDLR}^{-/-} /$human C-reactive protein transgenic mice. Thromb Haemost. (2008) 99:196201. doi: 10.1160/TH07-10-0595

75. Kovacs A, Tornvall P, Nilsson R, Tegnér J, Hamsten A, Björkegren J. Human C-reactive protein slows atherosclerosis development in a mouse model with human-like hypercholesterolemia. Proc Natl Acad Sci USA. (2007) 104:13768-73. doi: 10.1073/pnas.0706027104

76. Koike T, Kitajima S, Yu Y, Nishijima K, Zhang J, Ozaki $\mathrm{Y}$, et al. Human C-reactive protein does not promote atherosclerosis in transgenic rabbits. Circulation. (2009) 120:208894. doi: 10.1161/CIRCULATIONAHA.109.872796

77. Teupser D, Weber O, Rao TN, Sass K, Thiery J, Fehling HJ. No reduction of atherosclerosis in C-reactive protein (CRP)-deficient mice. J Biol Chem. (2011) 286:6272-9. doi: 10.1074/jbc.M110.161414

78. Yu Q, Liu Z, Waqar AB, Ning B, Yang X, Shiomi M, et al. Effects of antisense oligonucleotides against $\mathrm{C}$-reactive protein on the development of atherosclerosis in WHHL rabbits. Mediators Inflamm. (2014) 2014:979132. doi: 10.1155/2014/979132

79. Caprio V, Badimon L, Di Napoli M, Fang W-H, Ferris GR, Guo B, et al. pCRP-mCRP dissociation mechanisms as potential targets for the development of small-molecule anti-inflammatory chemotherapeutics. Front Immunol. (2018) 9:1089. doi: 10.3389/fimmu.2018.01089

80. Eisenhardt SU, Habersberger J, Murphy A, Chen Y-C, Woollard KJ, Bassler $\mathrm{N}$, et al. Dissociation of pentameric to monomeric C-reactive protein on activated platelets localizes inflammation to atherosclerotic plaques. Circ Res. (2009) 105:128-37. doi: 10.1161/CIRCRESAHA.108.190611

81. Molins B, Peña E, de la Torre R, Badimon L. Monomeric C-reactive protein is prothrombotic and dissociates from circulating pentameric C-reactive protein on adhered activated platelets under flow. Cardiovasc Res. (2011) 92:328-37. doi: $10.1093 / \mathrm{cvr} / \mathrm{cvr} 226$

82. Braig D, Kaiser B, Thiele JR, Bannasch H, Peter K, Stark GB, et al. A conformational change of C-reactive protein in burn wounds unmasks its proinflammatory properties. Int Immunol. (2014) 26:46778. doi: 10.1093/intimm/dxu056

83. Singh SK, Hammond DJ Jr, Beeler BW, Agrawal A. The binding of Creactive protein, in the presence of phosphoethanolamine, to low-density lipoproteins is due to phosphoethanolamine-generated acidic pH. Clin Chim Acta. (2009) 409:143-4. doi: 10.1016/j.cca.2009.08.013

84. Boncler M, Kehrel B, Szewczyk R, Stec-Martyna E, Bednarek R, Brodde $\mathrm{M}$, et al. Oxidation of C-reactive protein by hypochlorous acid leads to the formation of potent platelet activator. Int J Biol Macromol. (2018) 107:2701-14. doi: 10.1016/j.ijbiomac.2017.10.159

85. Goda T, Miyahara Y. Calcium-independent binding of human C-reactive protein to lysophosphatidylcholine in supported planar phospholipid monolayers. Acta Biomater. (2017) 48:20614. doi: 10.1016/j.actbio.2016.10.043

86. Goda T, Miyahara Y. Specific binding of human C-reactive protein towards supported monolayers of binary and engineered phospholipids. Colloids Surf B Biointerfaces. (2018) 161:662-9. doi: 10.1016/j.colsurfb.2017.11.036

87. Khreiss T, József L, Potempa LA, Filep JG. Conformational rearrangement in C-reactive protein is required for proinflammatory actions on human endothelial cells. Circulation. (2004) 109:201622. doi: 10.1161/01.CIR.0000125527.41598.68

88. Nunomura W, Hatakeyama M. Binding of low density lipoprotein (LDL) to C-reactive protein (CRP): A possible binding through apolipoprotein B in LDL at phosphorylcholine-binding site of CRP. Hokkaido Igaku Zasshi. (1990) 65:474-80.

89. Saxena U, Nagpurkar A, Dolphin PJ, Mookerjea S. A study on the selective binding of apoprotein B- and E-containing human plasma lipoproteins to immobilized rat serum phosphorylcholine-binding protein. J Biol Chem. (1987) 262:3011-16.

90. Taskinen S, Kovanen PT, Jarva H, Meri S, Pentikäinen MO. Binding of Creactive protein to modified low-density-lipoprotein particles: Identification of cholesterol as a novel ligand for C-reactive protein. Biochem J. (2002) 367:403-12. doi: 10.1042/bj20020492

91. Li H-Y, Wang J, Meng F, Jia Z-K, Su Y, Bai Q-F, et al. An intrinsically disordered motif mediates diverse actions of monomeric C-reactive protein. J Biol Chem. (2016) 291:8795-804. doi: 10.1074/jbc.M115.695023

92. Singh SK, Thirumalai A, Hammond DJ Jr, Pangburn MK, Mishra VK, Johnson DA, et al. Exposing a hidden functional site of C-reactive protein by site-directed mutagenesis. J Biol Chem. (2012) 287:35508. doi: 10.1074/jbc.M111.310011

93. Pathak A, Singh SK, Agrawal A. C-reactive protein is an atheroprotective molecule. J Immunol. (2018) 200:170.16.

94. Sjöwall C, Bengtsson AA, Sturfelt G, Skogh T. Serum levels of autoantibodies against monomeric C-reactive protein are correlated with disease activity in systemic lupus erythematosus. Arthrit Res Ther. (2004) 6:R8794. doi: $10.1186 / \operatorname{ar} 1032$

95. Wetterö J, Nilsson L, Jonasson L, Sjöwall C. Reduced serum levels of autoantibodies against monomeric C-reactive protein (CRP) in patients with acute coronary syndrome. Clin Chim Acta. (2009) 400:12831. doi: 10.1016/j.cca.2008.10.002

96. Tan Y, Yu F, Yang H, Chen M, Fang Q, Zhao M-H. Autoantibodies against monomeric C-reactive protein in sera from patients with lupus nephritis are associated with disease activity and renal tubulointerstitial lesions. Hum Immunol. (2008) 69:840-4. doi: 10.1016/j.humimm.2008. 09.006

97. Shi P, Li X-X, Zhu W, Yang H, Dong C, Li X-M. Immunohistochemical staining reveals $\mathrm{C}$-reactive protein existing predominantly as altered conformation forms in inflammatory lesions. Acta Biol Hung. (2014) 65:26573. doi: 10.1556/ABiol.65.2014.3.3

98. Thiele JR, Zeller J, Bannasch H, Stark GB, Peter K, Eisenhardt SU. Targeting $\mathrm{C}$-reactive protein in inflammatory disease by preventing conformational changes. Mediators Inflamm. (2015) 2015:372432. doi: 10.1155/2015/372432

99. Thiele JR, Habersberger J, Braig D, Schmidt Y, Goerendt K, Maurer V, et al. Dissociation of pentameric to monomeric C-reactive protein localizes and aggravates inflammation: in vivo proof of a powerful proinflammatory mechanism and a new anti-inflammatory strategy. Circulation. (2014) 130:35-50. doi: 10.1161/CIRCULATIONAHA.113.007124

100. Ji S-R, Wu Y, Potempa LA, Liang Y-H, Zhao J. Effect of modified Creactive protein on complement activation: a possible complement regulatory role of modified or monomeric C-reactive protein in atherosclerotic lesions. Arterioscler Thromb Vasc Biol. (2006) 26:935-41. doi: 10.1161/01.ATV.0000206211.21895.73

101. Wang M-Y, Ji S-R, Bai C-J, El Kebir D, Li H-Y, Shi J-M, et al. A redox switch in $\mathrm{C}$-reactive protein modulates activation of endothelial cells. FASEB J. (2011) 25:3186-96. doi: 10.1096/fj.11-182741

102. Endres M. Statins: potential new indications in inflammatory conditions. Atheroscler Suppl. (2006) 7:315. doi: 10.1016/j.atherosclerosissup.2006.01.005

103. Ridker PM, Cannon CP, Morrow D, Rifai N, Rose LM, McCabe CH, et al. C-reactive protein levels and outcomes after statin therapy. $N$ Engl J Med. (2005) 352:20-8. doi: 10.1056/NEJMoa042378

104. Nissen SE, Tuzcu EM, Schoenhagen P, Crowe T, Sasiela WJ, Tsai J, et al. Statin therapy, LDL cholesterol, C-reactive protein, and coronary artery disease. $N$ Engl J Med. (2005) 352:29-38. doi: 10.1056/NEJMoa042000

105. Strandberg TE, Vanhanen H, Tikkanen MJ. Effect of statins on C-reactive protein in patients with coronary artery disease. Lancet. (1999) 353:1189. doi: 10.1016/S0140-6736(05)76154-7 
106. Kleemann R, Verschuren L, de Rooij BJ, Lindeman J, de Maat MM, Szalai AJ, et al. Evidence for anti-inflammatory activity of statins and $\operatorname{PPAR} \alpha$ activators in human C-reactive protein transgenic mice in vivo and in cultured human hepatocytes in vitro. Blood. (2004) 103:418894. doi: 10.1182/blood-2003-11-3791

107. Verschuren L, Kleemann R, Offerman EH, Szalai AJ, Emeis SJ, Princen HMG, et al. Effect of low dose atorvastatin versus diet-induced cholesterol lowering on atherosclerotic lesion progression and inflammation in apolipoprotein E* 3-leiden transgenic mice. Arterioscler Thromb Vasc Biol. (2005) 25:1617. doi: 10.1161/01.ATV.0000148866.29829.19

108. Trion A, de Maat M, Jukema W, Maas A, Offerman E, Havekes L, et al. Anti-atherosclerotic effect of amlodipine, alone and in combination with atorvastatin, in $\mathrm{APOE}^{*}$ 3-leiden / $\mathrm{hCRP}$ transgenic mice. J Cardiovasc Pharmacol. (2006) 47:89-95. doi: 10.1097/01.fjc.0000195603.65858.27

109. Voleti B, Agrawal A. Statins and nitric oxide reduce C-reactive protein production while inflammatory conditions persist. Mol Immunol. (2006) 43:891-6. doi: 10.1016/j.molimm.2005.06.045

110. Arnaud C, Burger F, Steffens S, Veillard NR, Nguyen TH, Trono $D$, et al. Statins reduce interleukin-6-induced C-reactive protein in human hepatocytes: new evidence for direct antiinflammatory effects of statins. Arterioscler Thromb Vasc Biol. (2005) 25:12316. doi: 10.1161/01.ATV.0000163840.63685.0c

111. Kaesemeyer WH, Caldwell RB, Huang J, Caldwell RW. Pravastatin sodium activates endothelial nitric oxide synthase independent of its cholesterol-lowering actions. J Am Coll Cardiol. (1999) 33:234-41. doi: 10.1016/S0735-1097(98)00514-2

112. Harris MB, Blackstone MA, Sood SG, Li C, Goolsby JM, Venema VJ, et al. Acute activation and phosphorylation of endothelial nitric oxide synthase by HMG-CoA reductase inhibitors. Am J Physiol Heart Circ Physiol. (2004) 287:H560-6. doi: 10.1152/ajpheart.00214.2004

113. Agrawal A. CRP after 2004. Mol Immunol. (2005) 42:92730. doi: 10.1016/j.molimm.2004.09.028

114. Ridker PM, Rifai N, Clearfield M, Downs JR, Weis SE, Miles JS, et al. Measurement of C-reactive protein for the targeting of statin therapy in the primary prevention of acute coronary events. N Engl J Med. (2001) 344:1959-65. doi: 10.1056/NEJM200106283442601

115. Gabay C, Kushner I. Acute-phase proteins and other systemic responses to inflammation. $N$ Engl J Med. (1999) 340:44854. doi: 10.1056/NEJM199902113400607
116. Agrawal A. Not only immunoglobulins, C-reactive protein too. $\mathrm{Mol}$ Immunol. (2013) 56:561-2. doi: 10.1016/j.molimm.2013.05.234

117. Ngwa DN, Gang TB, Singh SK, Agrawal A. Engineered C-reactive protein with improved protective action against pneumococcal infection. J Immunol. (2016) 196:63.4.

118. Ngwa DN, Singh SK, Gang TB, Agrawal A. A C-reactive protein-based strategy to reduce antibiotic dosing. J Immunol. (2018) 200:170.14.

119. Ngwa DN, Agrawal A. Structure-function relationships of Creactive protein in bacterial infection. Front Immunol. (2019) 10:166. doi: 10.3389/fimmu.2019.00166

120. Miller YI, Choi S-H, Wiesner P, Fang L, Harkewicz R, Hartvigsen K, et al. Oxidation-specific epitopes are danger-associated molecular patterns recognized by pattern recognition receptors of innate immunity. Circ Res. (2011) 108:235-48. doi: 10.1161/CIRCRESAHA.110.2 23875

121. Stewart CR, Tseng AA, Mok Y-F, Staples MK, Schiesser CH, Lawrence $\mathrm{LJ}$, et al. Oxidation of low-density lipoproteins induces amyloid-like structures that are recognized by macrophages. Biochemistry. (2005) 44:9108-16. doi: 10.1021/bi050497v

122. Jones NR, Pegues MA, McCrory MA, Kerr SW, Jiang H, Sellati R, et al. Collagen-induced arthritis is exacerbated in C-reactive proteindeficient mice. Arthrit Rheum. (2011) 63:2641-50. doi: 10.1002/art. 30444

123. Pathak A, Singh SK, Thirumalai A, Armstrong PB, Agrawal A. Evolution of a host-defense function of C-reactive protein from horseshoe crab to humans. J Immunol. (2016) 196:132.5.

124. Pathak A, Agrawal A. Evolution of C-reactive protein. Front Immunol. (2019) 10:943. doi: 10.3389 /fimmu.2019.00943

Conflict of Interest Statement: The authors declare that the research was conducted in the absence of any commercial or financial relationships that could be construed as a potential conflict of interest.

Copyright (๑) 2019 Singh and Agrawal. This is an open-access article distributed under the terms of the Creative Commons Attribution License (CC BY). The use, distribution or reproduction in other forums is permitted, provided the original author(s) and the copyright owner(s) are credited and that the original publication in this journal is cited, in accordance with accepted academic practice. No use, distribution or reproduction is permitted which does not comply with these terms. 